\title{
Performance Base Design of Multi-Storey Steel Structures Considering Dynamic Loads Originated by Geological Agents
}

\section{Bhatti $A Q^{*}$ and Naqash $M T$}

Civil Engineering Department, Islamic University in Madinah, Kingdom of Saudia Arabia

\begin{abstract}
Dynamic stresses generated by geological agents such as earthquakes, sand storms and hurricanes causes great damages to the structures. In this research dynamic loads the effect of generated by these geological agents have been taken into account for the performance base evaluation and design of rigid steel frames. The effect of fundamental periods on the design of these frames taking into account the variation in the behaviour factor and drift limitations is highlighted. The periods are obtained from the modal dynamic analysis; their performances were tested through nonlinear pushover analysis and these are then compared with the periods obtained from codified formulations. The weight of the designed frames are normalised with respect to the modal periods. It is observed that as the drift limitation varies from the lower limit (relaxed one) to the upper limit (stringent one); the fundamental period of the frames decreases and so the stiffness of the frame increases due to the members (beam and columns) sizes. Furthermore, it can be noted that the periods calculated from the codified formulations are in the same range to the one obtained from the modal analysis when the strict drift limit is incorporated.
\end{abstract}

Keywords: Fundamental periods; Seismic codes; Drift limitations; Steel frames; Behaviour factor

\section{Introduction}

Earthquakes, tsunamis, sand storms and hurricanes are extremely for the building infrastructure, example includes Structures irreparably damaged by the quake included nearly 400,000 buildings, numerous elevated road and rail bridges during 1995 Great Hanshin earthquake in Kobe Japan and about $81 \%$ of the housing units were damaged during Hurricane Katrina. In the above context Dynamic design of buildings is extremely vital however under current fragile global economic trends performance base cost effective infrastructure design is very crucial.

Structural design subjected to natural hazards; cyclones and earthquakes requires performance to remain safe and sound. The acceptable level of performance of structures in each mode of vibration is governed by fundamental period and damping, these reveals remarkable effect on the magnitude of its response to later forces and therefore on the overall performance of the entire framing structure. Better prediction of such characteristics (periods/mode of vibrations and damping) at the design stage surely enable safe design of structures. Equations specified by building codes are used for calculating the fundamental periods which are the then used to estimate the design base shear and lateral forces along the building height. Structural codes offer equations; depends on the constructional material, horizontal load resisting system and height, Goel and Chopra [1], Lagomarsino [2], Tamura and Suganuma [3] and Tremblay and Rogers [4] have carried out several studies on the dynamic features of rigid frames. In critics; most of the structural codes adopt the formula suggested by Goel and Chopra [1] that does not incorporate the effect of several parameters such as the in-plan geometry and asymmetry of the building. In this paper, numerical studies are carried using CSI code SAP 2000 [5] by modal analysis for low- and medium-rise buildings to examine the fundamental period of vibration. It includes the influence of drift limitations and the ductility of the frames.

The greater part of the advanced foundation is helpless against dynamic anxieties; produced by topographical specialists, for example, seismic occasions and subsequently among a few seismic load opposing frameworks it is trusted that inflexible steel outlines carries on much adaptable and accordingly offer ascend to high crucial time of vibrations. In basic outline when seismic is overseeing, the time of the building is basic in assessing the base shear and subsequently the parallel powers along the stature relying upon the method of vibration. Most seismic codes indicate experimental formulae to assess the crucial time of vibration for structures, these are utilized for both low-and medium-ascent structures and as cited before rely upon the materials of development (steel, fortified solid, brick work and so forth.), building sorts (Moment opposing edge, Braced edges, Shear divider and so forth.) and general measurements of the structures [6]. Heretofore, it has been witnessed that the fundamental period of vibration obtained from the formulation when based on the codes is about $50 \%$ lower than the one determined by modal response spectrum analysis. This disagreement between the two is due to the fact that simplified formulae given by seismic codes underestimate it; based on empirical evaluation, therefore globally accounting also for the stiffening effects of non-structural elements such as partition walls and in fills (glass etc.). These effects are evidently of high consideration for steel frames which display comparatively lesser stiffness; which further give rise to conservative design conventions e.g., higher design acceleration (consequently high seismic base shear) and in turn bigger Interstorey drifts [7].

\section{Fundamental periods}

The formulation for estimating the approximate fundamental period of structural frames varies from code to code; these formulations

*Corresponding author: Abdul Qadir Bhatti, Associate Professor, Civil Engineering Department, Islamic University in Madinah, Kingdom of Saudia Arabia, Tel: +966 14847 4080; E-mail: draqbhatti@iu.edu.sa

Received August 04, 2017; Accepted October 04, 2017; Published October 13 2017

Citation: Bhatti AQ, Naqash MT (2017) Performance Base Design of Multi-Storey Steel Structures Considering Dynamic Loads Originated by Geological Agents. J Steel Struct Constr 3: 134. doi: 10.4172/2472-0437.1000134

Copyright: @ 2017 Bhatti AQ, et al. This is an open-access article distributed under the terms of the Creative Commons Attribution License, which permits unrestricted use, distribution, and reproduction in any medium, provided the original author and source are credited. 
Citation: Bhatti AQ, Naqash MT (2017) Performance Base Design of Multi-Storey Steel Structures Considering Dynamic Loads Originated by Geological Agents. J Steel Struct Constr 3: 134. doi: 10.4172/2472-0437.1000134

Page 2 of 10

as suggested in building codes are used to calculate the design base shear. For example, in order to estimate the fundamental period of building structures NEHRP provisions [8] recommend a simplified formula for Reinforced concrete and steel Moment resisting frame buildings given by eqn. (1)

$$
T=N_{S / 10}
$$

where $N_{s}$ denotes the number of storeys.

The NEHRP formulation is further restricted to (a) buildings not exceeding 12 stories in height and (b) having a minimum story height of $10 \mathrm{ft}$. Goel and Chopra [1] suggested an expression as given in eqn.

(2) being highly conservative.

$$
T=C_{t}(H)^{0.75}
$$

Where $\mathrm{H}$ denotes height of the building in feet above the base; and the numerical coefficient $\mathrm{C}_{\mathrm{t}}$ denotes 0.030 and 0.035 for $\mathrm{RC}$ and steel MRF buildings, respectively.

Eurocode 8 [9] recommends quite similar formulae as that of Goel and Chopra. For buildings with heights of up to $40 \mathrm{~m}$ the value of $T_{1}$ (sec) may be approximated by the following eqn. (3).

$$
T_{1}=C_{t}(H)^{3 / 4}
$$

Where, $\mathrm{C} t$ is:

0.085 for moment resistant steel frames,

0.075 for moment resistant concrete frames and for eccentrically braced steel frames and

\subsection{0 for all other structures;}

$H$ is the height of the building in meters from the foundation or from the top of a rigid basement.

\section{Parametric analysis}

A parametric analysis has been conducted on 9, 7 and 5 storeys

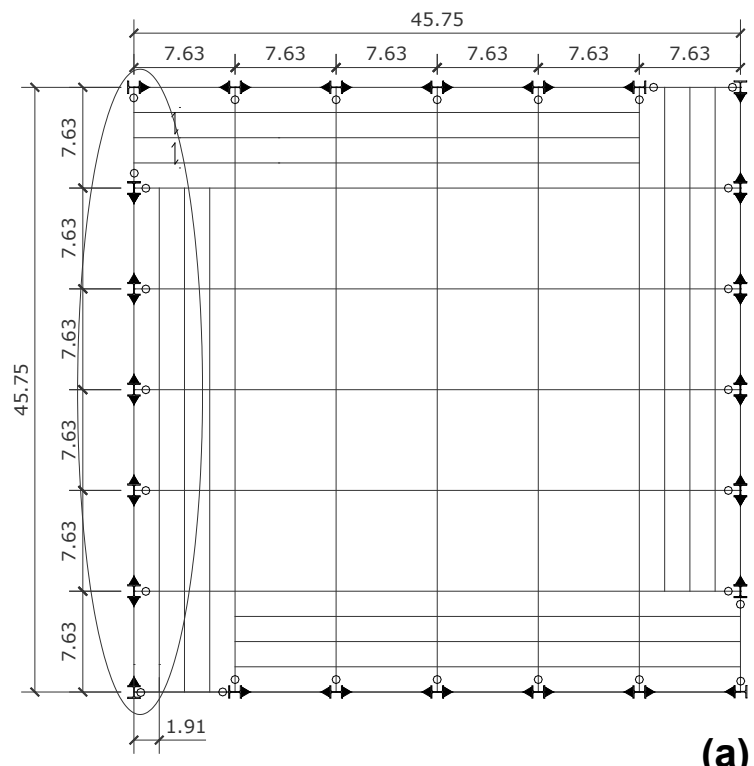

regular buildings (typical floor plan of the structure with 6 bays is shown in Figure 1) with different spans $(9.15 \mathrm{~m}, 7.63 \mathrm{~m}, 6.54 \mathrm{~m}$ and 5.08 $\mathrm{m}$ ) with the purpose to analyse the fundamental period and further to compare it with the code values for rigid steel frame. The floor to floor height is $4 \mathrm{~m}$ therefore give rise to a total height of $36 \mathrm{~m}, 28 \mathrm{~m}$ and $20 \mathrm{~m}$ for 9,7 and 5 storeys frames, respectively. In perimeter configuration, the building plan is considered to be composed of steel MRFs as lateral load resisting system along the perimeter.

Table 1 summarized the analysed frames with the anticipated parameters; these include span and number of bays, behaviour factors and the damageability criteria etc. Modal response spectrum procedure and pushover analysis have been carried out for all the adopted combinations (144 designed cases).

\section{Assumptions for the Design of frames}

Reference is made to EC0 [10] and EC1 [11] for vertical (gravity) loads acting on the adopted frames, give rise to a total gravity loading (structural and non-structural) of about $4.6 \mathrm{kN}$ on a square meter for roof and $7.8 \mathrm{kN}$ on a square meter for typical floor; these values include imposed (Live) load of $0.4 \mathrm{kN}$ on a square meter for roof and $3.0 \mathrm{kN}$ on a square meter for typical floor. All the framing members (beams and columns) are designed using EN 10025-2 S275 grade structural steel.

A bay width of $2.29 \mathrm{~m}$ is assumed for the secondary beams; simply supported with such an orientation to provide an optimized structural grid. The flooring system is composed of COMFLOR-46 system [12], using A252 mesh, and is comprised of $145 \mathrm{~mm}$ thick concrete slab having $0.9 \mathrm{~mm}$ thick steel sheeting. The masses according to EC8 for the frames are $589 \mathrm{kN}-\mathrm{sec}^{2} / \mathrm{m}$ for typical floor, while for roof these are 491 $\mathrm{kN}-\mathrm{sec}^{2} / \mathrm{m}$ and therefore masses on each frame for 9,7 and 5 storeys are 5203, 4025 and $2847491 \mathrm{kN}-\mathrm{sec}^{2} / \mathrm{m}$, respectively. The reference frames are designed according to EC 8 with the assumed design $\mathrm{q}$ factor ( $\mathrm{q}=6.5,4,3$ and 2 ) using general-purpose civil-engineering software SAP 2000 [5], considering type $C$ soil stratigraphic profile (dense sand or gravel or stiff soil), important class II $\left(\gamma_{\mathrm{I}}=1.0\right)$, type 1 elastic response

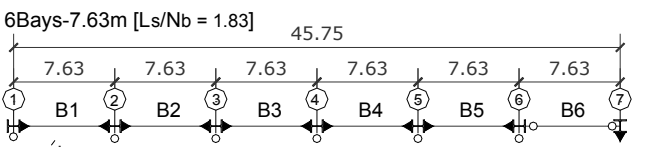

- Rigid beam to column connection

- Pinned beam to column connection

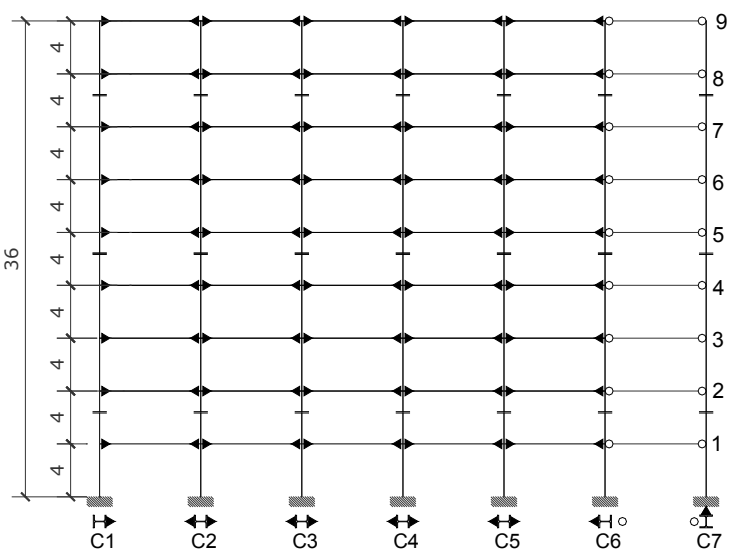

(b)

Figure 1: Typical floor plan of 6 Bays perimeter MRFs (a) and perimeter frame elevation (b) (1 m=3.28 ft). 
Citation: Bhatti AQ, Naqash MT (2017) Performance Base Design of Multi-Storey Steel Structures Considering Dynamic Loads Originated by Geological Agents. J Steel Struct Constr 3: 134. doi: 10.4172/2472-0437.1000134

Page 3 of 10

\begin{tabular}{|c|c|c|c|c|c|c|}
\hline Case & No & Floor to Floor Height H) & Bays (Span width) & $\mathbf{q}$ & $\Delta / \mathrm{h}$ & Combination \\
\hline \multirow[t]{3}{*}{ c1 } & $1,2,3,4$ & \multirow{3}{*}{$5(\mathrm{H}=20 \mathrm{~m})$} & \multirow{9}{*}{$\begin{array}{l}5(9.15 \mathrm{~m}) \\
6(7.63 \mathrm{~m}) \\
7(6.54 \mathrm{~m}) \\
9(5.08 \mathrm{~m})\end{array}$} & \multirow{9}{*}{$\begin{array}{l}\text { High Ductility } \\
-6.5\end{array}$} & $\mathrm{~L} 1=0.01$ & Comb-1 \\
\hline & $5,6,7,8$ & & & & $\mathrm{~L} 2=0.0075$ & Comb-2 \\
\hline & $9,10,11,12$ & & & & $L 3=0.005$ & Comb-3 \\
\hline \multirow[t]{3}{*}{$\mathrm{c} 2$} & $13,14,15,16$ & \multirow{3}{*}{$7(\mathrm{H}=28 \mathrm{~m})$} & & & $\mathrm{L} 1=0.01$ & Comb-1 \\
\hline & $17,18,19,20$ & & & & $\mathrm{~L} 2=0.0075$ & Comb-2 \\
\hline & $21,22,23,24$ & & & & $L 3=0.005$ & Comb-3 \\
\hline \multirow[t]{3}{*}{ c3 } & $25,26,27,28$ & \multirow{3}{*}{$9(\mathrm{H}=36 \mathrm{~m})$} & & & $\mathrm{L} 1=0.01$ & Comb-1 \\
\hline & $29,30,31,32$ & & & & $\mathrm{~L} 2=0.0075$ & Comb-2 \\
\hline & $33,34,35,36$ & & & & $L 3=0.005$ & Comb-3 \\
\hline \multirow[t]{3}{*}{$\mathrm{c} 4$} & $37,38,39,40$ & \multirow{3}{*}{$5(\mathrm{H}=20 \mathrm{~m})$} & \multirow{9}{*}{$\begin{array}{l}5(9.15 \mathrm{~m}) \\
6(7.63 \mathrm{~m}) \\
7(6.54 \mathrm{~m}) \\
9(5.08 \mathrm{~m})\end{array}$} & \multirow{9}{*}{$\begin{array}{c}\text { MEDIUM DUCTILITY } \\
-4\end{array}$} & $L 1=0.01$ & Comb-4 \\
\hline & $41,42,43,44$ & & & & $\mathrm{~L} 2=0.0075$ & Comb-5 \\
\hline & $45,46,47,48$ & & & & $L 3=0.005$ & Comb-6 \\
\hline c5 & $49,50,51,52$ & \multirow{3}{*}{$7(\mathrm{H}=28 \mathrm{~m})$} & & & $\mathrm{L} 1=0.01$ & Comb-4 \\
\hline & $53,54,55,56$ & & & & L2 $=0.0075$ & Comb-5 \\
\hline & $57,58,59,60$ & & & & $\mathrm{~L} 3=0.005$ & Comb-6 \\
\hline \multirow[t]{3}{*}{$\mathrm{c} 6$} & $61,62,63,64$ & \multirow{3}{*}{$9(\mathrm{H}=36 \mathrm{~m})$} & & & $\mathrm{L} 1=0.01$ & Comb-4 \\
\hline & $65,66,67,68$ & & & & $\mathrm{~L} 2=0.0075$ & Comb-5 \\
\hline & $69,70,71,72$ & & & & $\mathrm{~L} 3=0.005$ & Comb-6 \\
\hline \multirow[t]{3}{*}{ c7 } & $73,74,75,76$ & \multirow{3}{*}{$5(\mathrm{H}=20 \mathrm{~m})$} & \multirow{9}{*}{$\begin{array}{l}5(9.15 \mathrm{~m}) \\
6(7.63 \mathrm{~m}) \\
7(6.54 \mathrm{~m}) \\
9(5.08 \mathrm{~m})\end{array}$} & \multirow{9}{*}{ CONVENTIONAL DUCTILITY (3.0) } & $L 1=0.01$ & Comb-7 \\
\hline & $77,78,79,80$ & & & & $\mathrm{~L} 2=0.0075$ & Comb-8 \\
\hline & $81,82,83,84$ & & & & $L 3=0.005$ & Comb-9 \\
\hline $\mathrm{c} 8$ & $85,86,87,88$ & \multirow{3}{*}{$7(\mathrm{H}=28 \mathrm{~m})$} & & & $L 1=0.01$ & Comb-7 \\
\hline & $89,90,91,92$ & & & & $\mathrm{~L} 2=0.0075$ & Comb-8 \\
\hline & $93,94,95,96$ & & & & $L 3=0.005$ & Comb-9 \\
\hline \multirow[t]{3}{*}{ c9 } & $97,98,99,100$ & \multirow{3}{*}{$9(\mathrm{H}=36 \mathrm{~m})$} & & & $\mathrm{L} 1=0.01$ & Comb-7 \\
\hline & $1,01,10,21,03,104$ & & & & $\mathrm{~L} 2=0.0075$ & Comb-8 \\
\hline & $1,05,10,61,07,108$ & & & & $L 3=0.005$ & Comb-9 \\
\hline \multirow[t]{3}{*}{$\mathrm{c} 10$} & $1,09,11,01,11,112$ & \multirow{3}{*}{$5(\mathrm{H}=20 \mathrm{~m})$} & \multirow{9}{*}{$\begin{array}{l}5(9.15 \mathrm{~m}) \\
6(7.63 \mathrm{~m}) \\
7(6.54 \mathrm{~m}) \\
9(5.08 \mathrm{~m})\end{array}$} & \multirow{9}{*}{$\begin{array}{c}\text { LOW DUCTILITY } \\
-2\end{array}$} & $\mathrm{~L} 1=0.01$ & Comb-10 \\
\hline & $1,13,11,41,15,116$ & & & & $\mathrm{~L} 2=0.0075$ & Comb-11 \\
\hline & $1,17,11,81,19,120$ & & & & $\mathrm{~L} 3=0.005$ & Comb-12 \\
\hline \multirow[t]{3}{*}{$\mathrm{c} 11$} & $1,21,12,21,23,124$ & & & & $\mathrm{~L} 1=0.01$ & Comb-10 \\
\hline & $1,25,12,61,27,128$ & $7(\mathrm{H}=28 \mathrm{~m})$ & & & $\mathrm{L} 2=0.0075$ & Comb-11 \\
\hline & $1,29,13,01,31,132$ & & & & $\mathrm{~L} 3=0.005$ & Comb-12 \\
\hline $\mathrm{c} 12$ & $1,33,13,41,35,136$ & & & & $\mathrm{~L} 1=0.01$ & Comb-10 \\
\hline & $1,37,13,81,39,140$ & $9(\mathrm{H}=36 \mathrm{~m})$ & & & L2 $=0.0075$ & Comb-11 \\
\hline & $141,142,143,144$ & & & & $L 3=0.005$ & Comb-12 \\
\hline
\end{tabular}

Table 1: Analyzed cases for 9,7 and 5 storey frames having different bay widths.

spectrum and $0.25 \mathrm{~g}$ peak ground acceleration. It is also important to underline that 1.6 torsional amplification factor as describe by EC8 is considered (as the analysis is performed by using two planner models so the torsional affect is determined by doubling the accidental eccentricity). Therefore the assumed PGA is amplified by torsion factor equals 1.6 (resulting within an overall PGA equals $0.4 \mathrm{~g}$ ).

Each frame is considered to be a perimeter frame (Figure 1) and in order to have symmetrically loaded frames with symmetrically oriented profiles each frame has a pinned connection at the corner bay [13].

EC8 recommends the capacity design approach for the design of members to have a global ductile behaviour of structure. In case of MRF, the weak beam and strong column concept should be followed. A flowchart for the prescribed design procedure is shown in Figure 2. From the flowchart, it is evident that the design is revised normally due to the re-evaluation of over strength factor $(\Omega)$ in Euro code 8 as it is related to the plastic resistance of beams. For the beams of MRF with classes 1 and 2 cross sections, the inequalities, in eqns. (4), (5) and (6) should be verified at the location where the formation of hinges is expected:

Moment inequality for the design of beams
$\frac{M_{E d}}{M_{P I, R d}} \leq 1.0$

Axial inequality for the design of beams

$$
\frac{N_{E d}}{N_{P I, R d}} \leq 0.15
$$

Shear inequality for the design of beams

$$
\frac{V_{E d}}{V_{P I, R d}} \leq 0.5
$$

The columns shall be verified in compression considering the most unfavourable combination of the axial force and bending moments.

\section{Over stiffness of frames}

In the following, over stiffness of the frames is calculated for each designed frame.

From these graphs (Figures 3-5), it is evident that mostly, drift criterion govern the design specially in the case of drift limit L2 and L3, showing that it is not useful if for such high ductility drift limit L2 


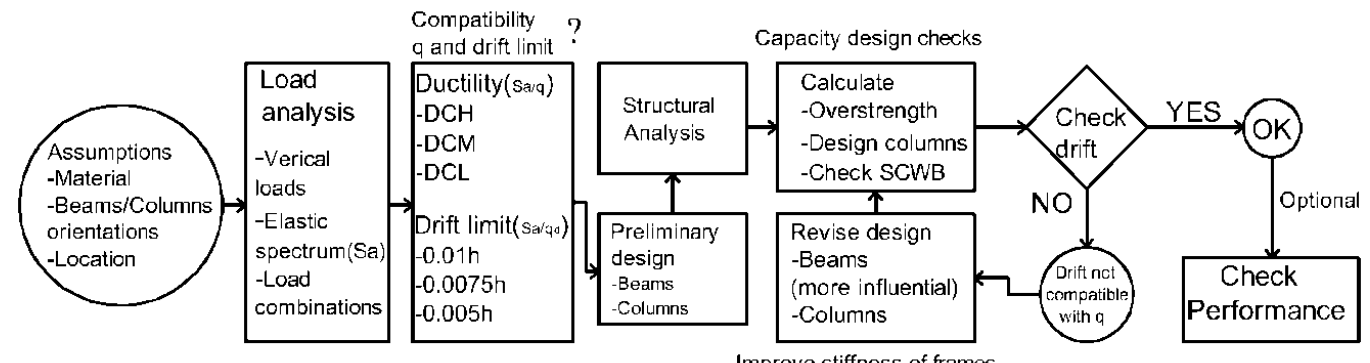

Figure 2: Capacity design flowchart for steel MRFs using Euro codes process.
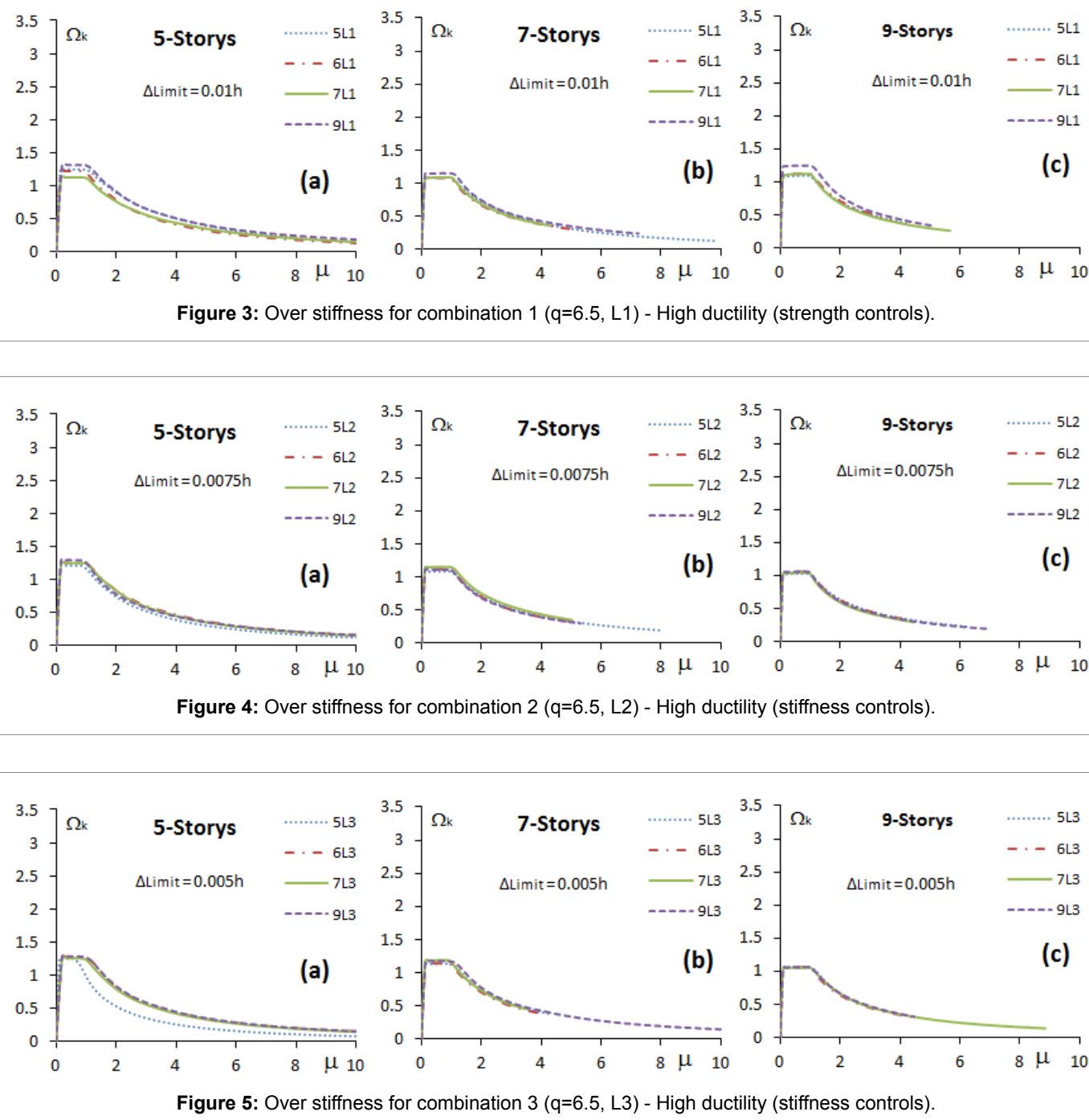

or L3 is used. As the q factor is not optimally used. For such cases and combinations It is suggested that for DCH only drift limit L1 can only be used optimally (Figures 6-8).

These graphs are related to DCM ( $q=4.0)$, interestingly as shown in Figure 6 the $\mathrm{q}$ factor is optimally used, as the strength govern the design, Instead for drift limit there is a question mark regard the optimum use of $\mathrm{q}$ factor, but for sure in the case of drift limit L3, the behaviour factor is not used optimally. Therefore it is suggested when dealing with drift limit L3, it is uneconomical to use the ductility class of Euro code 8 as they behaviour factor cannot be used optimally. Therefore, for DCM drift limit L1 and L2 are preferable (Figures 9-11).

When managing float restricts $\mathrm{L} 3$, it is proposed that $\mathrm{q}=3.0$ can be utilized. Here q=3.0, can be ideally utilized, however it ought to be remember that the outlined profile are immense as the float foundation is as yet critical and facilitate it is to be noticed that the computed over strength is very high. These elements can be inspected in the worry 
Citation: Bhatti AQ, Naqash MT (2017) Performance Base Design of Multi-Storey Steel Structures Considering Dynamic Loads Originated by Geological Agents. J Steel Struct Constr 3: 134. doi: 10.4172/2472-0437.1000134

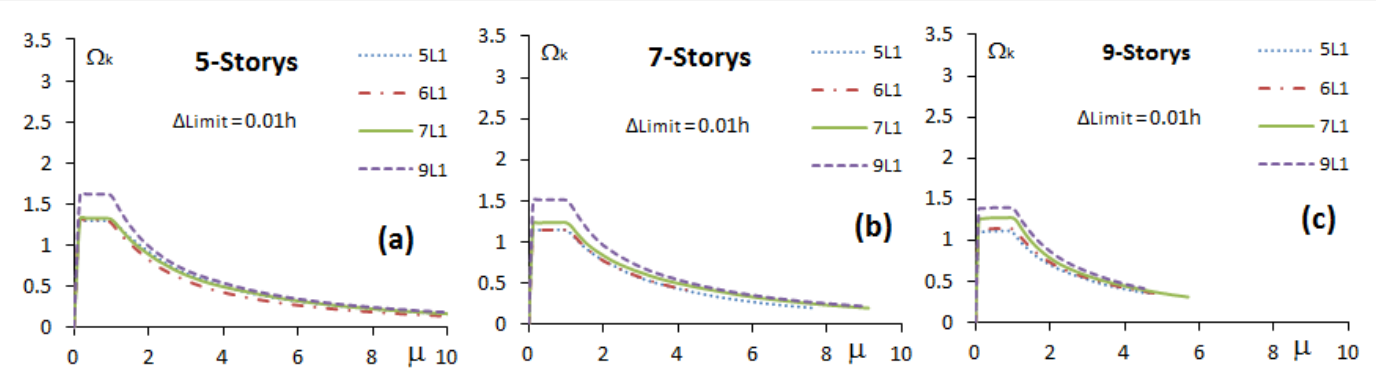

Figure 6: Over stiffness for combination $4(q=4, L 1)$ - Medium ductility (strength controls).

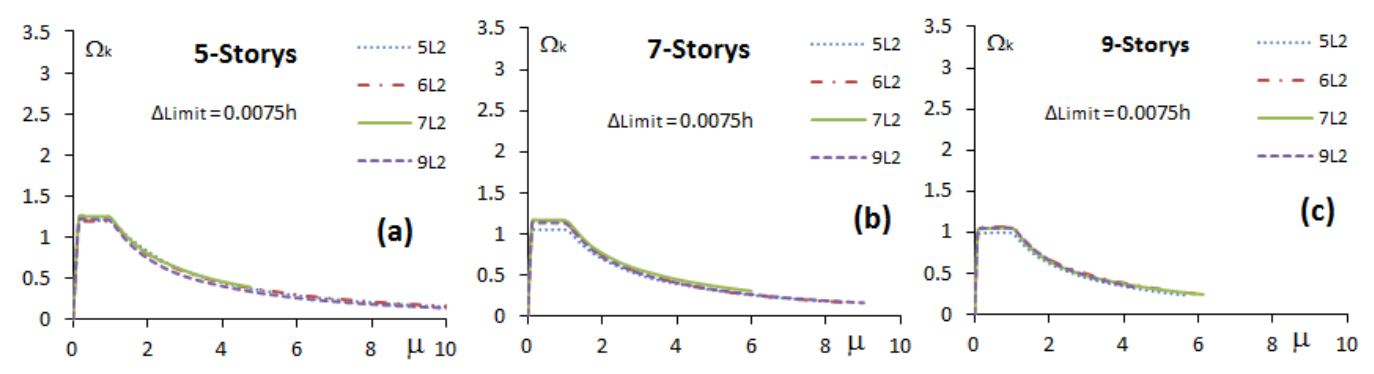

Figure 7: Over stiffness for combination 5 ( $q=4, \mathrm{~L} 2)$ - Medium ductility (strength/stiffness controls).
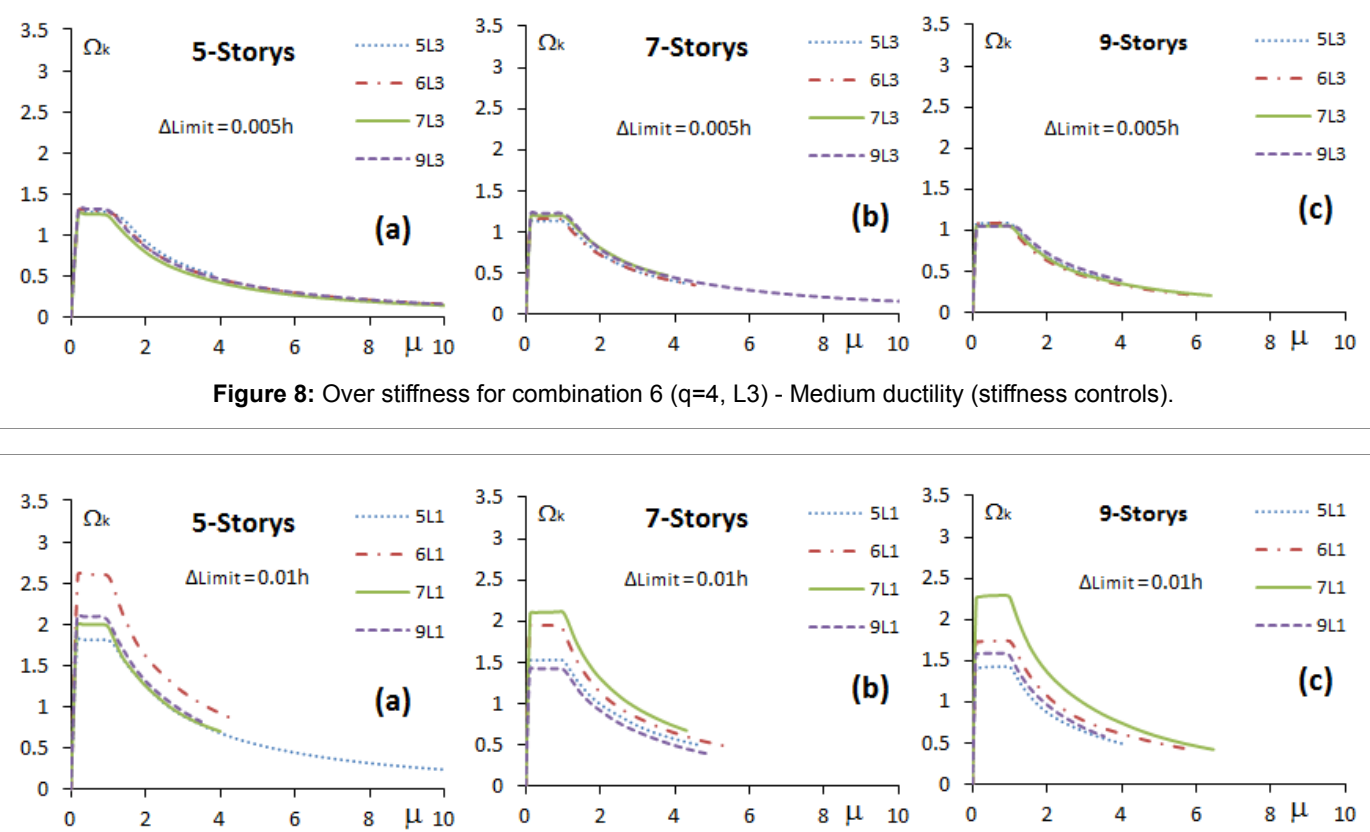

Figure 9: Over stiffness for combination 7 ( $q=3, L 1)$ - Conventional ductility (strength controls).

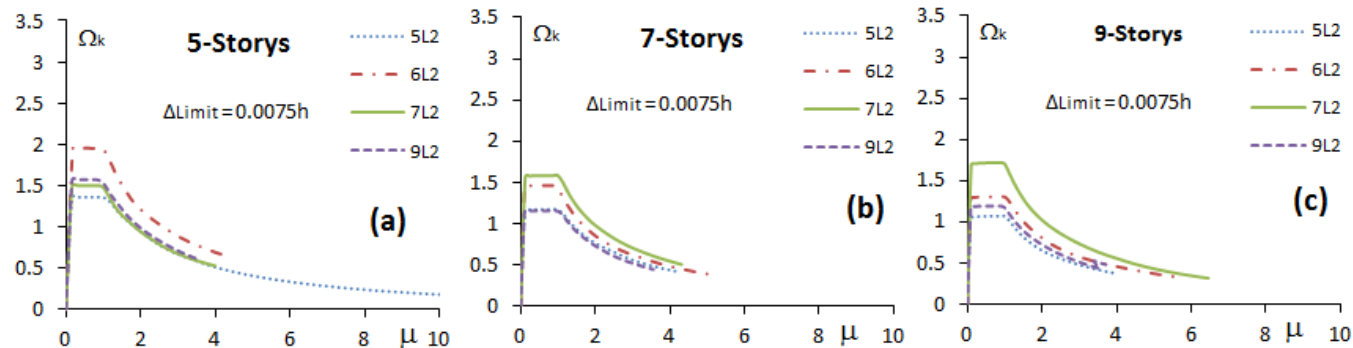

Figure 10: Over stiffness for combination $8(q=3, L 2)$ - Conventional ductility (strength controls). 
Citation: Bhatti AQ, Naqash MT (2017) Performance Base Design of Multi-Storey Steel Structures Considering Dynamic Loads Originated by Geological Agents. J Steel Struct Constr 3: 134. doi: 10.4172/2472-0437.1000134

Page 6 of 10

segment of computed over strength and in the profile network also from the heaviness of the casings (Figures 12-14).

When elastic analysis is used, all the drift limits (L1, L2 and L3) are automatically satisfied. This means that the code specified limit especially L3 is directly related to the elastic analysis. When the frame satisfy drift limitation, $\Omega_{\mathrm{k}}=1.0$, when $\Omega_{\mathrm{k}}>1.0$ means that the design is governed by strength and frame is considered overstiff. The frames with over stiffness close to 1.0 are optimally design with stiffness (SLS). If drift limitation govern, q cannot be optimally used and leads to uneconomical design situation, thereby, paying extra due to the assumed ductility together with paying for deformability.

\section{Fundamental periods}

By and large building tallness speaks to itself as a known parameter preceding any points of interest plan and it portray the proportion amongst firmness and mass of the building. In this way, in the vast majority of the auxiliary codes for seismic plan, for example, Euro code 8 the estimation of the basic time frame is given by a definition which is an element of the aggregate tallness $(\mathrm{H})$ of the structure. Though in unique examination the major time frame is identified with the solidness and mass of the edges; and with the progressions of Interstorey float, the firmness and the time of the structure differ. The code detailing is
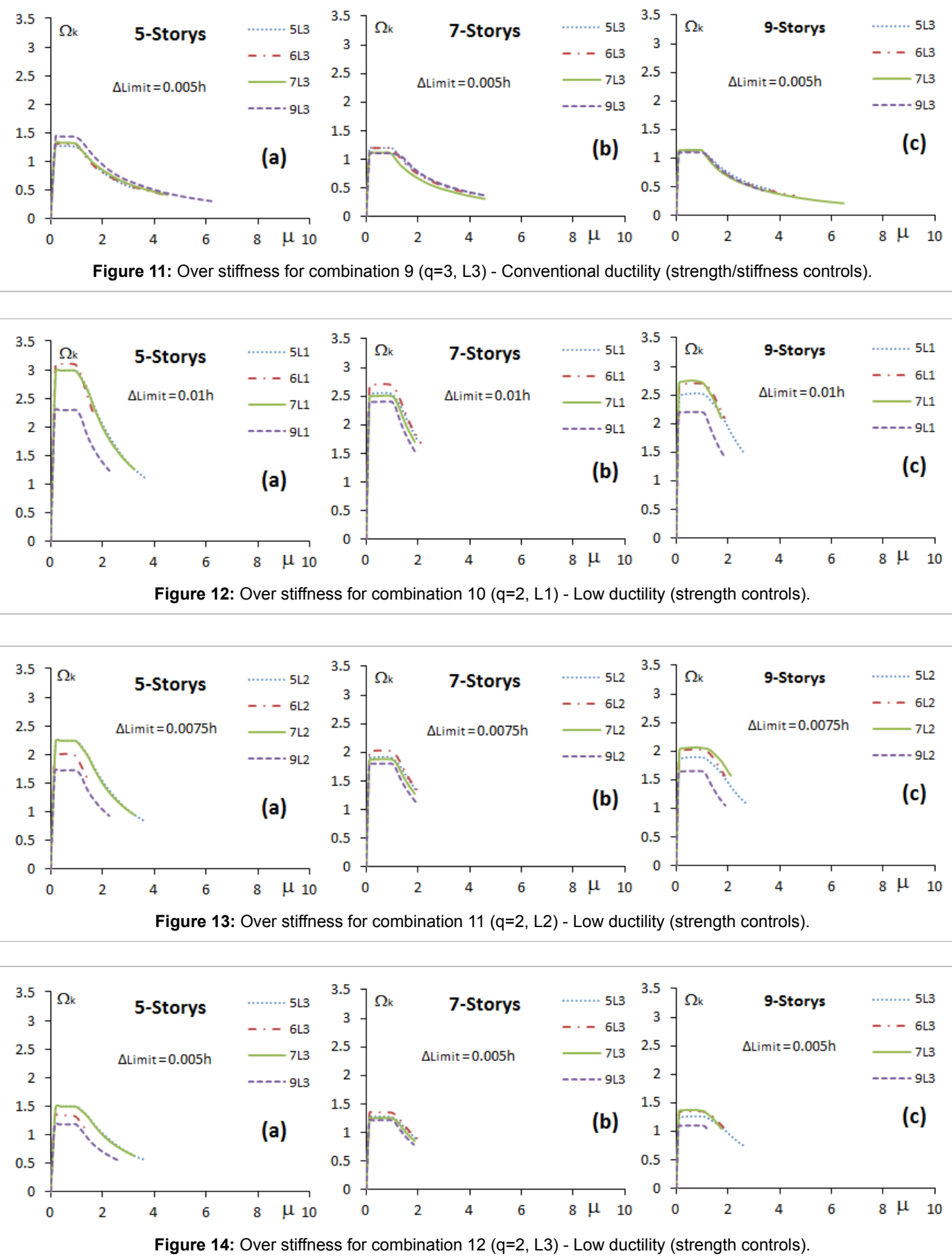
Citation: Bhatti AQ, Naqash MT (2017) Performance Base Design of Multi-Storey Steel Structures Considering Dynamic Loads Originated by Geological Agents. J Steel Struct Constr 3: 134. doi: 10.4172/2472-0437.1000134

Page 7 of 10

just a component of the stature of the casing and is regardless from the quantity of narrows, the firmness of the edges and from the float confinements. The central time frame is straightforwardly identified with the utilization of conduct factor $\mathrm{q}$ and clearly too as far as possible. Table 2 demonstrates the Fundamental time frames for the embraced cases (Figures 2 and 3); these are typically more prominent than the code determined period.

In order to see the variation between the fundamental periods obtained from modal analysis and those obtained from the codified formulation, normalised values are provided in Table 3 . These values are also provided in Figure 15 (for 5 and 6 bays) and in Figure 16 (for 7 and 9 bays).

The code specified fundamental period is almost equal to the modal period when the frames are designed with the most strict drift limit $(0.005 \mathrm{~h})$ as clear from Figures 15 and 16. In this case the frames have sufficient stiffness to satisfy the code proposed drift limit. Instead, the period is high and therefore less stiff when the drift limit $(0.0075 \mathrm{~h})$ and $(0.01 \mathrm{~h})$ are employed in the design.

\begin{tabular}{|c|c|c|c|c|c|c|c|c|c|c|c|c|c|}
\hline \multirow[t]{2}{*}{ Comb } & \multirow[t]{2}{*}{ Drift Limit } & \multicolumn{3}{|c|}{5 Bays } & \multicolumn{3}{|c|}{6 Bays } & \multicolumn{3}{|c|}{7 Bays } & \multicolumn{3}{|c|}{9 Bays } \\
\hline & & $5-S$ & $7-S$ & 9-S & $5-S$ & $7-S$ & 9-S & $5-S$ & $7-S$ & 9-S & $5-S$ & $7-S$ & 9-S \\
\hline $\mathrm{c} 1$ & \multirow[t]{4}{*}{ L1 (0.01 h) } & 0.79 & 0.53 & 0.43 & 0.76 & 0.53 & 0.44 & 0.72 & 0.53 & 0.44 & 0.78 & 0.57 & 0.49 \\
\hline $\mathrm{c} 4$ & & 0.83 & 0.56 & 0.45 & 0.81 & 0.56 & 0.44 & 0.81 & 0.58 & 0.5 & 0.95 & 0.7 & 0.53 \\
\hline c7 & & 1.1 & 0.73 & 0.57 & 1.54 & 0.91 & 0.68 & 1.18 & 0.95 & 0.83 & 1.18 & 0.66 & 0.59 \\
\hline c10 & & 1.72 & 1.18 & 0.93 & 1.75 & 1.22 & 0.96 & 1.69 & 1.14 & 1 & 1.33 & 1.05 & 0.79 \\
\hline $\mathrm{c} 2$ & \multirow[t]{4}{*}{ L2 (0.0075 h) } & 0.98 & 0.68 & 0.53 & 1 & 0.7 & 0.55 & 0.98 & 0.71 & 0.54 & 1 & 0.69 & 0.53 \\
\hline c5 & & 0.98 & 0.68 & 0.52 & 0.97 & 0.72 & 0.55 & 1 & 0.72 & 0.54 & 0.95 & 0.7 & 0.53 \\
\hline c8 & & 1.1 & 0.74 & 0.57 & 1.54 & 0.91 & 0.68 & 1.18 & 0.95 & 0.83 & 1.18 & 0.71 & 0.59 \\
\hline c11 & & 1.72 & 1.18 & 0.93 & 1.59 & 1.22 & 0.96 & 1.69 & 1.14 & 1 & 1.33 & 1.05 & 0.79 \\
\hline c3 & \multirow[t]{4}{*}{ L3 (0.005 h) } & 1.49 & 1.02 & 0.79 & 1.52 & 1.02 & 0.78 & 1.47 & 1.04 & 0.78 & 1.45 & 1.03 & 0.78 \\
\hline c6 & & 1.52 & 1.02 & 0.8 & 1.54 & 1.04 & 0.81 & 1.47 & 1.05 & 0.78 & 1.47 & 1.06 & 0.76 \\
\hline c9 & & 1.52 & 1.1 & 0.85 & 1.54 & 1.08 & 0.83 & 1.54 & 1 & 0.83 & 1.61 & 0.99 & 0.78 \\
\hline $\mathrm{c} 12$ & & 1.72 & 1.18 & 0.93 & 1.59 & 1.22 & 0.96 & 1.69 & 1.14 & 1 & 1.39 & 1.06 & 0.79 \\
\hline
\end{tabular}

Table 2: Fundamental period $(T)$ in sec for all the analysed cases.

\begin{tabular}{|c|c|c|c|c|c|c|c|c|c|c|c|c|c|}
\hline \multirow[t]{2}{*}{ Comb } & \multirow[t]{2}{*}{ Drift Limit } & \multicolumn{3}{|c|}{5 Bays } & \multicolumn{3}{|c|}{6 Bays } & \multicolumn{3}{|c|}{7 Bays } & \multicolumn{3}{|c|}{9 Bays } \\
\hline & & $5-S$ & $7-S$ & 9-S & $5-S$ & $7-S$ & 9-S & $5-S$ & 7-S & 9-S & $5-S$ & $7-S$ & 9-S \\
\hline $\mathrm{c} 1$ & \multirow[t]{4}{*}{ L1 (0.01 h) } & 1.58 & 1.83 & 1.87 & 1.63 & 1.81 & 1.83 & 1.72 & 1.82 & 1.81 & 1.59 & 1.7 & 1.65 \\
\hline$c 4$ & & 1.51 & 1.73 & 1.79 & 1.54 & 1.74 & 1.81 & 1.53 & 1.66 & 1.61 & 1.31 & 1.37 & 1.5 \\
\hline c7 & & 1.13 & 1.32 & 1.41 & 0.81 & 1.06 & 1.18 & 1.06 & 1.01 & 0.96 & 1.06 & 1.46 & 1.36 \\
\hline c10 & & 0.72 & 0.82 & 0.86 & 0.71 & 0.79 & 0.83 & 0.73 & 0.85 & 0.8 & 0.93 & 0.92 & 1.01 \\
\hline $\mathrm{c} 2$ & \multirow[t]{4}{*}{ L2 $(0.0075 \mathrm{~h})$} & 1.27 & 1.41 & 1.5 & 1.24 & 1.37 & 1.46 & 1.27 & 1.36 & 1.49 & 1.24 & 1.4 & 1.5 \\
\hline c5 & & 1.27 & 1.43 & 1.54 & 1.28 & 1.34 & 1.45 & 1.24 & 1.34 & 1.49 & 1.31 & 1.37 & 1.5 \\
\hline $\mathrm{c} 8$ & & 1.13 & 1.3 & 1.41 & 0.81 & 1.06 & 1.17 & 1.06 & 1.01 & 0.96 & 1.06 & 1.35 & 1.36 \\
\hline c11 & & 0.72 & 0.82 & 0.86 & 0.78 & 0.79 & 0.83 & 0.73 & 0.85 & 0.8 & 0.93 & 0.92 & 1.01 \\
\hline c3 & \multirow[t]{4}{*}{ L3 $(0.005$ h) } & 0.83 & 0.95 & 1.02 & 0.82 & 0.95 & 1.03 & 0.85 & 0.93 & 1.02 & 0.86 & 0.94 & 1.03 \\
\hline $\mathrm{c} 6$ & & 0.82 & 0.95 & 1 & 0.81 & 0.93 & 0.99 & 0.85 & 0.92 & 1.03 & 0.85 & 0.91 & 1.05 \\
\hline c9 & & 0.82 & 0.88 & 0.94 & 0.81 & 0.9 & 0.96 & 0.81 & 0.97 & 0.96 & 0.77 & 0.98 & 1.02 \\
\hline c12 & & 0.72 & 0.82 & 0.86 & 0.78 & 0.79 & 0.83 & 0.73 & 0.85 & 0.8 & 0.9 & 0.91 & 1.02 \\
\hline
\end{tabular}

Table 3: Modal analysis period normalised to code prescribed period.
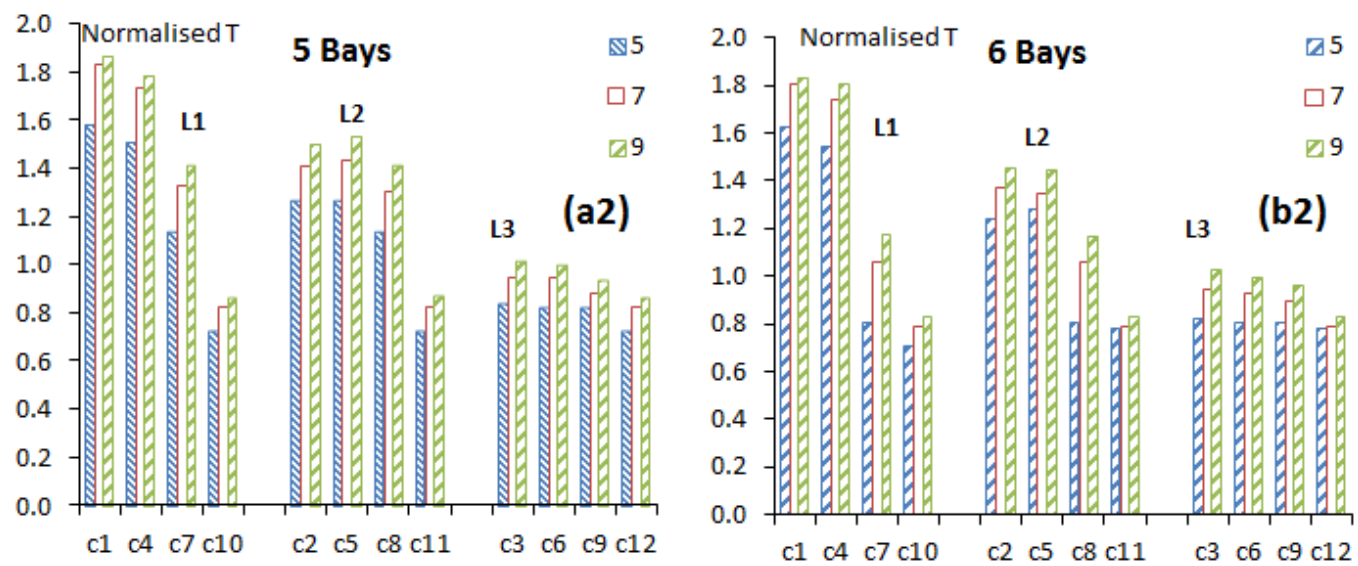

Figure 15: Modal analysis period normalised to code prescribed period for 5 bays ( $a 1$ and a2) and for 6 bays (b1 and b2). 

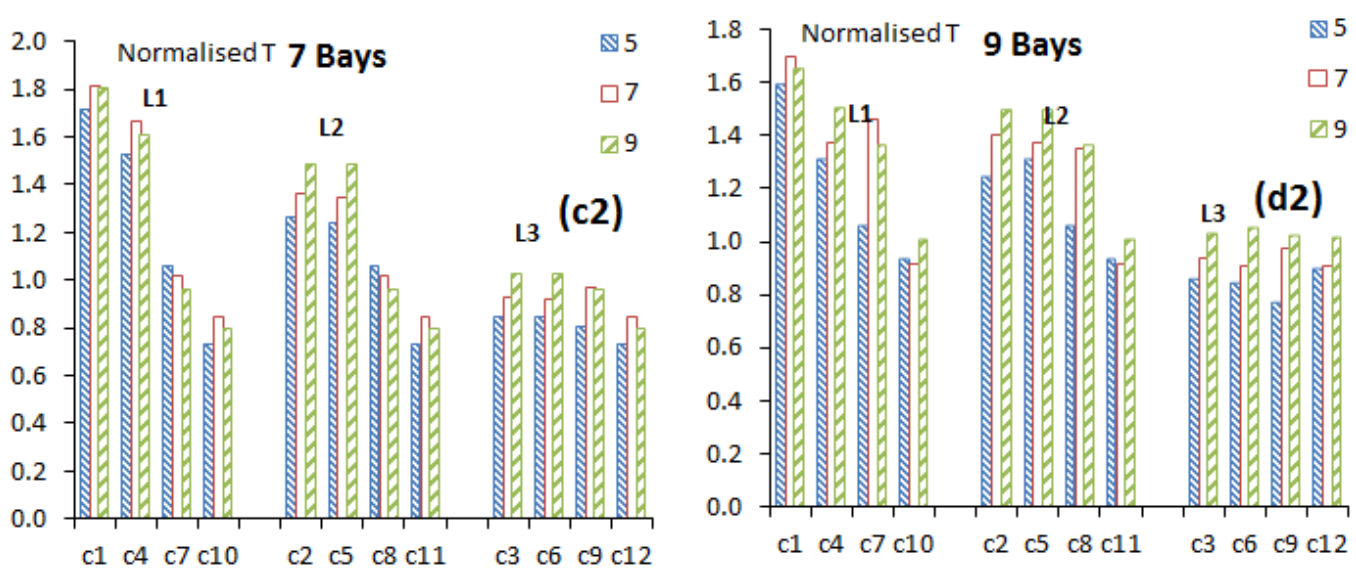

Figure 16: Modal analysis period normalised to code prescribed period for 7 bays (c1 and c2) and for 9 bays (d1 and d2)
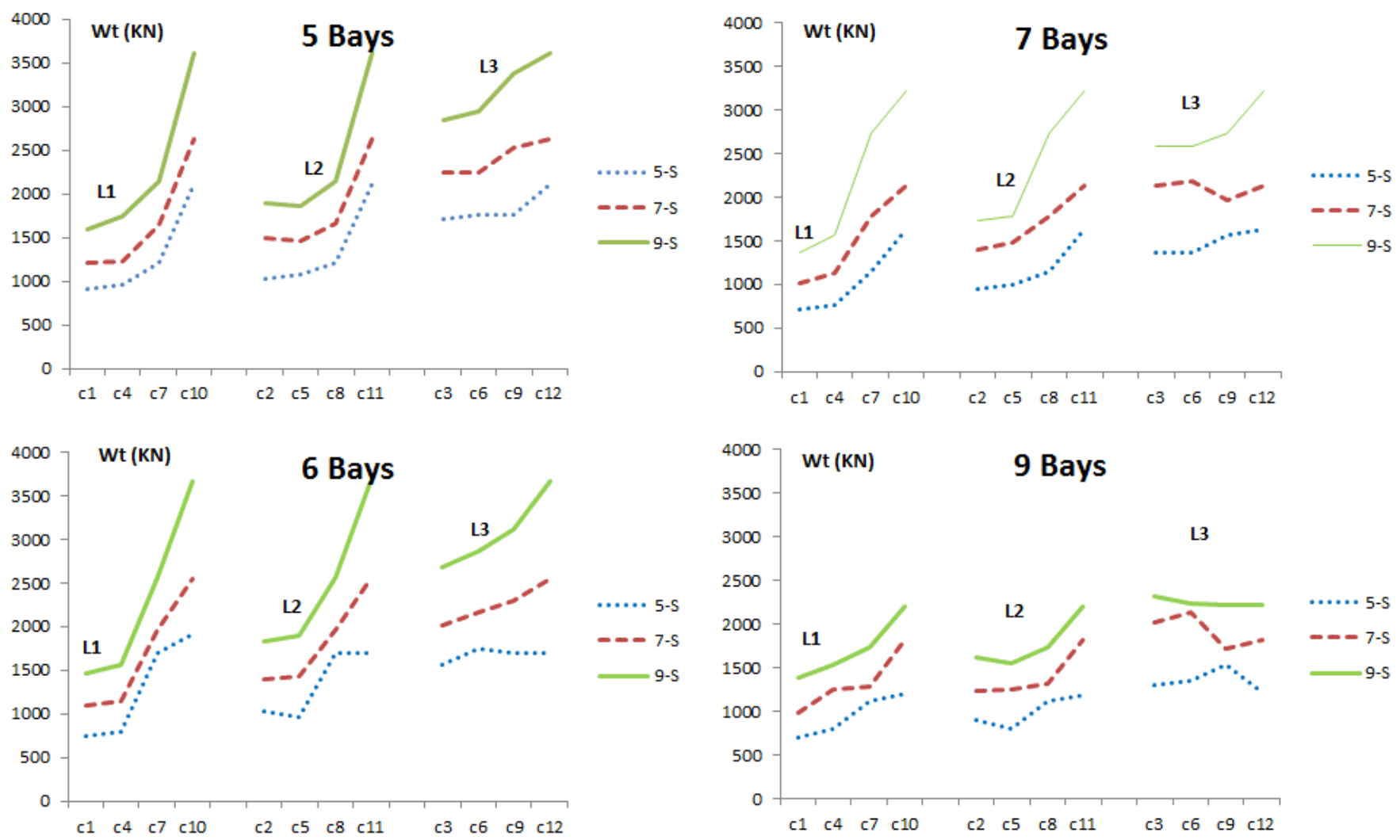

Figure 17: Weight of frames for 5, 6, 7 and 9 bay frames.

\section{Cost effectiveness}

Cost of steel structures is generally expresses in term of steel weight as commercially available in different geographic regions. In the following the weight of steel is calculated for the designed frames. From Figure 17, it is obvious that the increases in the weight of frames for 5 bays is quite high when the $\mathrm{q}$ factor is reducing (going from $\mathrm{DCH}$ to DCL), nevertheless the increase in the weight of frames for 9 bays is less, which shows that as the stiffness of the frame increases ductility classes does not have a big influence on the weight of frames.

These are then normalised to the fundamental period obtained from the modal analysis for all the cases (Figures 18 and 19).

Interestingly almost same results (weight normalised to time period) are obtained for DCH and DCM in all the cases. Moreover for 5 bays these are similar even for the assumed conventional ductility class where behaviour factor consider is only 3.0 (Table 4 ).

\section{Conclusions}

\section{Analysis results (Technical)}

The fundamental period directly affect the performance and weight of frames. It is observed that with the increases in the weight of frames 

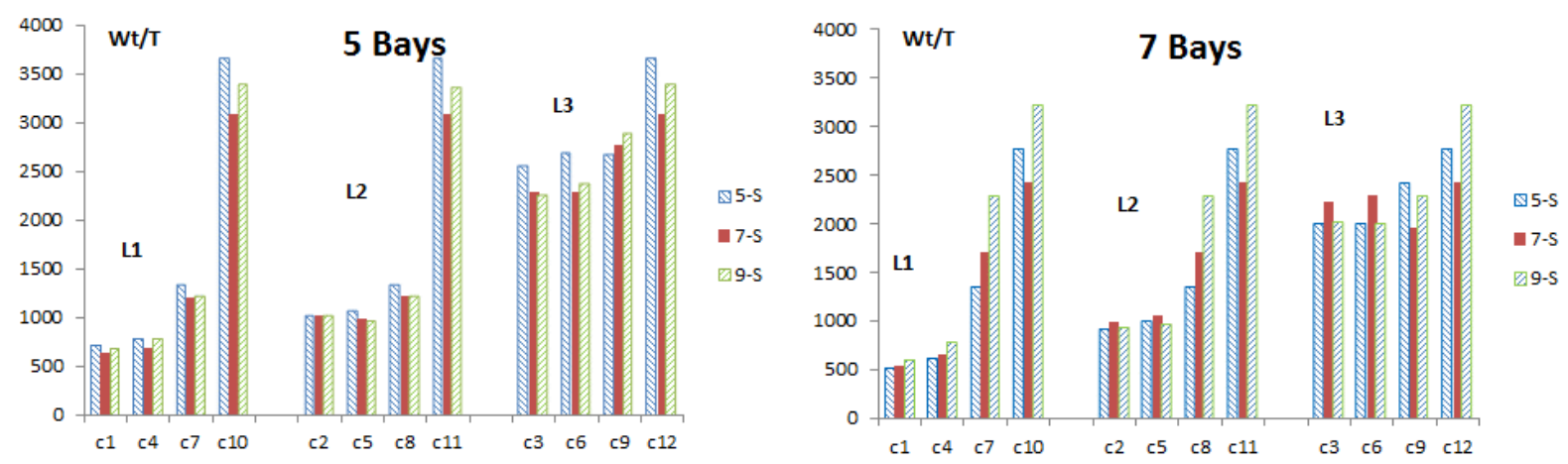

Figure 18: Weight of frames normalised to period for 5 bays (left) and for 7 bays (right).
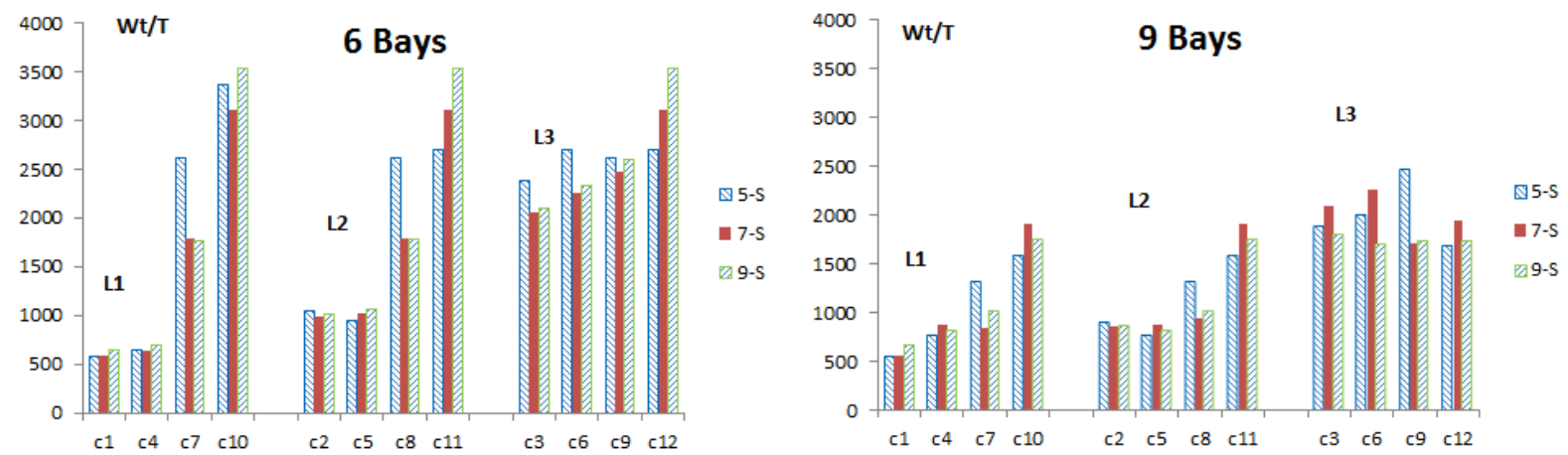

Figure 19: Weight of frames normalised to period for 6 bays (left) and for 9 bays (right).

\begin{tabular}{|c|c|c|c|c|c|c|c|c|c|c|c|c|c|}
\hline \multirow[t]{2}{*}{ Comb } & \multirow[t]{2}{*}{ Drift Limit } & \multicolumn{3}{|c|}{5 Bays } & \multicolumn{3}{|c|}{6 Bays } & \multicolumn{3}{|c|}{7 Bays } & \multicolumn{3}{|c|}{9 Bays } \\
\hline & & $5-S$ & $7-S$ & 9-S & $5-S$ & $7-S$ & 9-S & $5-S$ & $7-S$ & 9-S & $5-S$ & $7-S$ & 9-S \\
\hline $\mathrm{c} 1$ & \multirow[t]{4}{*}{ L1 (0.01 h) } & 717 & 644 & 687 & 580 & 589 & 641 & 513 & 538 & 606 & 554 & 562 & 674 \\
\hline $\mathrm{c} 4$ & & 793 & 688 & 785 & 647 & 639 & 694 & 619 & 662 & 778 & 769 & 882 & 820 \\
\hline c7 & & 1341 & 1206 & 1219 & 2615 & 1790 & 1753 & 1361 & 1705 & 2287 & 1315 & 846 & 1022 \\
\hline $\mathrm{c} 10$ & & 3660 & 3094 & 3388 & 3365 & 3116 & 3530 & 2776 & 2425 & 3225 & 1593 & 1917 & 1754 \\
\hline c2 & \multirow[t]{4}{*}{ L2 $(0.0075 \mathrm{~h})$} & 1021 & 1032 & 1017 & 1036 & 987 & 1006 & 927 & 991 & 934 & 909 & 857 & 865 \\
\hline c5 & & 1062 & 996 & 977 & 940 & 1035 & 1056 & 1001 & 1066 & 963 & 768 & 882 & 830 \\
\hline c8 & & 1341 & 1233 & 1219 & 2615 & 1790 & 1765 & 1361 & 1705 & 2287 & 1315 & 937 & 1022 \\
\hline $\mathrm{c} 11$ & & 3660 & 3094 & 3356 & 2697 & 3116 & 3530 & 2776 & 2425 & 3225 & 1592 & 1917 & 1754 \\
\hline c3 & \multirow[t]{4}{*}{ L3 $(0.005$ h) } & 2560 & 2296 & 2247 & 2376 & 2065 & 2088 & 2000 & 2225 & 2022 & 1891 & 2089 & 1805 \\
\hline c6 & & 2685 & 2296 & 2365 & 2694 & 2266 & 2322 & 2000 & 2301 & 2006 & 2001 & 2267 & 1711 \\
\hline c9 & & 2680 & 2786 & 2895 & 2615 & 2478 & 2598 & 2420 & 1966 & 2286 & 2468 & 1704 & 1736 \\
\hline $\mathrm{c} 12$ & & 3660 & 3094 & 3389 & 2697 & 3116 & 3530 & 2776 & 2425 & 3226 & 1694 & 1941 & 1744 \\
\hline
\end{tabular}

Table 4: Weight of frames normalized to the fundamental period of vibrations.

for 5 bays is quite high when the $\mathrm{q}$ factor is reducing; nevertheless the increase in the weight of frames for 9 bays is less, which shows that as the stiffness of the frame increases ductility classes does not have a big influence on the weight of frames. From the designed cases it is evident that the when the drift limit of the EC8 varies from the more relax limit to the stringent one the fundamental period decreases which shows that the code specified fundamental period is almost equal to the modal period when the frames are designed with the most strict drift limit $(0.005 \mathrm{~h})$, whereas it is higher in the case of drift limit $(0.0075$ $\mathrm{h})$ and $(0.01 \mathrm{~h})$. This implies the period given by the code could be acquired from the modular investigation of the edge when composed with strict float constraint. Besides this presumes, the code determined major period is emphatically identified with the expected float constrain as various float restrict causes to have distinctive firmness and subsequently key period. Likewise when the edge fulfil float impediment the Over stiffness of the edges equivalents to solidarity, when over stiffness increments than solidarity implies that the outline is represented by quality and casing is considered overstaff. The casings with over stiffness near solidarity are ideally plan with firmness (SLS). On the off chance that float restriction oversee, q can't be ideally utilized and prompts uneconomical plan circumstance, in this manner, paying additional because of the expected flexibility together with paying for deformability.

\section{Conflict of Interest}

"The authors declare that there is no conflict of interest regarding the publication of this paper. 
Citation: Bhatti AQ, Naqash MT (2017) Performance Base Design of Multi-Storey Steel Structures Considering Dynamic Loads Originated by Geological Agents. J Steel Struct Constr 3: 134. doi: 10.4172/2472-0437.1000134

Page 10 of 10

\section{References}

1. Goel RK, Chopra AK (1997) Period formulas for moment-resisting frame buildings. Civil and Environmental Engineering, p: 62.

2. Lagomarsino S (1993) Forecast models for damping and vibration periods of buildings. Journal of Wind Engineering and Industrial Aerodynamics 48: 221239

3. Tamura Y, Suganuma SY (1996) Evaluation of amplitude-dependent damping and natural frequency of buildings during strong winds. Journal of Wind Engineering and Industrial Aerodynamics 59: 115-130.

4. Tremblay R, Rogers C (2005) Impact of capacity design provisions and period limitations on the seismic design of low-rise steel buildings. International Journal of Steel Structures 5: 1-22.

5. Computer and Structures Incorporation (CSI) (1978) SAP 2000 Users Manual Berkeley, California, USA: Computer and Structures.

6. Cinitha A, Umesha PK, lyer NR (2012) A Rational Approach for Fundamental
Period of Low and Medium Rise Steel Building Frames. International Journal of Modern Engineering Research (IJMER) 2: 6.

7. Naqash MT, Matteis GD, Luca AD (2012) Seismic design of Steel Moment Resisting frames-European Versus American Practice. NED University Journal of Research, pp: 45-59.

8. William TH (2000) The 1997 NEHRP recommended provisions for seismic regulations for new buildings and Other Structures. Earthquake Spectra 16 $101-114$.

9. http://files.isec.pt/DOCUMENTOS/SERVICOS/BIBLIO/Documentos $\% 20$ de\%20acesso\%20remoto/Eurocode-8-1-Earthquakes-general.pdf

10. http://eurocodes.jrc.ec.europa.eu/doc/WS2008/EN1991_2_Malakatas.pdf

11. http://www.phd.eng.br/wp-content/uploads/2015/12/en.1991.1.1.2002.pdf

12. http://www.comflor-uk.com/

13. Naqash MT (2013) Optimum design of Steel Moment Resisting Frames using Eurocode. University of Chiete and Pescara, Pescara. 